\title{
Long-Range Displacement Sensor Based on SMS Fiber Structure and OTDR
}

\author{
A. ARIFIN ${ }^{1,3 *}$, A. M. HATTA ${ }^{2,4}$, SEKARTEDJO $^{2}$, M. S. MUNTINI ${ }^{1}$, and \\ A. RUBIYANTO ${ }^{1}$ \\ ${ }^{1}$ Department of Physics, Institut Teknologi Sepuluh Nopember, Surabaya 60111, Indonesia \\ ${ }^{2}$ Departement of Engineering Physics, Institut Teknologi Sepuluh Nopember, Surabaya 6011, Indonesia \\ ${ }^{3}$ Department of Physics, Hasanuddin University, Makassar 90245, Indonesia \\ ${ }^{4}$ Department of Physics, Jazan University, Jazan 45-142, Saudi Arabia \\ *Corresponding author: A. ARIFINＥ-mail: arifinpide@gmail.com
}

\begin{abstract}
This paper presents a long-range displacement measurement method by using a singlemulti-single mode (SMS) fiber structure, attached to a flexible plate between two permanent poles and the optical time domain reflectometer (OTDR)-based interrogator. The SMS fiber structure sensors are prepared with two different configurations, i.e. straight and sinusoidal configurations. It is demonstrated that the displacement sensor can perform a displacement measurement with a range from $0 \mathrm{~mm}$ to $150 \mathrm{~mm}$ with a resolution of $0.159 \mathrm{~mm}$. The sinusoidal configuration provides a better sensitivity than the straight configuration. The proposed sensor offers a low cost, and it can be implemented for quasi-distributed displacement measurement which is suitable for civil structure monitoring.
\end{abstract}

Keywords: Displacement sensor, SMS fiber structure, OTDR

Citation: A. ARIFIN, A. M. HATTA, SEKARTEDJO, M. S. MUNTINI, and A. RUBIYANTO, "Long-Range Displacement Sensor Based on SMS Fiber Structure and OTDR," Photonic Sensors, 2015, 5(2): 166-171.

\section{Introduction}

Several types of optical fiber sensors have been proposed to measure a displacement for civil structure monitoring. It is known that the optical fiber sensors have some advantages when they are compared to the conventional sensors. The optical fiber sensor, in general, is invulnerable to the electromagnetic interference, small size, light weight, and high sensitivity, and it is able to perform remote measurement and easy for multiplexing [1].

There are some types of developed optical fiber sensors for the displacement measurement. Fiber
Bragg grating (FBG)-based sensors have been widely investigated for displacement measurement in the civil structures [2]. In [3], a configuration was proposed for a long-range displacement measurement by using the FBG sensor. The FBGs have also been developed for many sensors applications such as temperature, humidity, and strain sensors [4]. However, in implementation of the FBG-based sensors, a complex interrogator is needed [5]. Other optical fiber sensor types based on multimode interference in the single-multi-single mode (SMS) fiber structure have been reported for the displacement measurement and their related

Received: 26 September 2014 / Revised version: 9 December 2014

(C) The Author(s) 2015. This article is published with open access at Springerlink.com

DOI: $10.1007 / \mathrm{s} 13320-015-0225-4$

Article type: Regular 
applications [6-9]. The SMS fiber structure-based sensors are easier to fabricate, and they have a lower cost than the FBG-based sensors. It was reported that its sensitivities for strain or temperature sensors are similar to that of the FBG [10].

A displacement sensor based on microbend in the SMS structure by using an intensity-based interrogation technique was reported more sensitive compared with the microbending in conventional fiber optics [6, 7]. A bending of the SMS fiber structure was proposed as the displacement sensor with a capability to distinguish the surrounding temperature simultaneously by using a wavelength shift-based interrogation technique [8]. So far, the proposed displacement sensors based on SMS fiber structures have a limited measurement range less than $1 \mathrm{~mm}[8]$.

In this paper, we propose a novel configuration based on the SMS fiber structure and an optical time domain reflectometer (OTDR)-based interrogation technique for a long-range displacement measurement. The use of the OTDR as an interrogator for the SMS fiber structure strain and temperature sensor was proposed previously, and the capability of quasi-distributed or multi-point measurement was demonstrated [11, 12]. In our configuration, the SMS fiber structure was installed on a flexible plate between two permanent poles. The applied displacement induced a bending on the SMS fiber structure attached to the plate. The SMS fiber structure's connection and the applied displacement on the SMS fiber structure can be detected as an event in the OTDR. Straight and sinusoidal arrangements of the SMS fiber structure attached to the plate were prepared, and a long-range displacement measurement of $150 \mathrm{~mm}$ was demonstrated.

\section{Experimental method}

The configuration of a long-range displacement measurement system based on the optical fiber sensor with SMS structure is shown in Fig. 1(a). The sensor was prepared by connecting a multimode fiber (MMF) graded index section between two step index of singlemode fibers (SMF) by means of a splicer of Sumitomo Electric type-25e and Fitel NC S324 as a precision fiber cutting equipment. The SMF type of SMF28 and the MMF graded index (ITU-T recommendation G.651) were used. The SMS fiber structure-based sensor with straight and sinusoidal arrangements was prepared with lengths of $100 \mathrm{~cm}, 90 \mathrm{~cm}, 80 \mathrm{~cm}$, and $70 \mathrm{~cm}$. The sensor with sinusoidal arrangement had an amplitude of $2.5 \mathrm{~cm}$ and a period of $5 \mathrm{~cm}$. Figure 1(b) shows the experimental setup of the straight (SMS-1) and sinusoidal (SMS-2) arrangements, respectively.

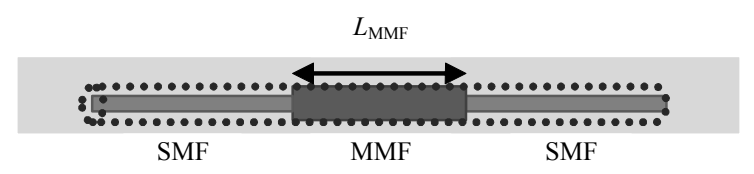

(a)

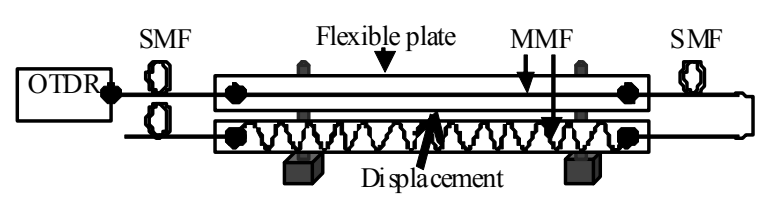

(b)

Fig. 1 Schematic diagram of the experimental setup (a) SMS fiber structure-based sensor and (b) straight and sinusoidal arrangements.

The SMS fiber structure was glued to a flexible plate. The distance between the two permanent poles was $60 \mathrm{~cm}$, and the length of the flexible plate was $100 \mathrm{~cm}$. The applied displacement was given by a millimeter displacement stage to the SMS fiber structure attached to the flexible plate between two permanent poles. The return loss was measured by Agilent Mini OTDR E6000C connected to the SMS fiber structure with an operational wavelength of $1310 \mathrm{~nm}$. When a displacement was applied to the flexible plate, a bending occurred to the SMS fiber structure attached to the plate. The bending can influence the transmission characteristic of the SMS fiber structure. Due to the bending in the SMS fiber structure, the multimode interference pattern in the MMF section of the SMS fiber structure changed [8]. This caused variation in the transmission and 
reflection of light which can be detected by the OTDR.

\section{Results and discussion}

The experimental setup was prepared to measure the displacement within a range from $0 \mathrm{~mm}$ to $150 \mathrm{~mm}$ and an increment of $5 \mathrm{~mm}$, and it was interrogated by using the OTDR. Figure 2 shows a logarithmic response of the OTDR measurement. The abscissa and the ordinate are represented by the location (in meter) and the return loss (in $\mathrm{dB}$ ), respectively, as shown in Fig. 2. In Fig.2(a), there are four events in the measurement: two reflective events refer to connectors to the OTDR and the end of the fiber, and the other two non-reflective events refer to the SMS fiber structure and the applied displacement as in the middle part of the graph, and it is zoomed as shown in Fig. 2(b).

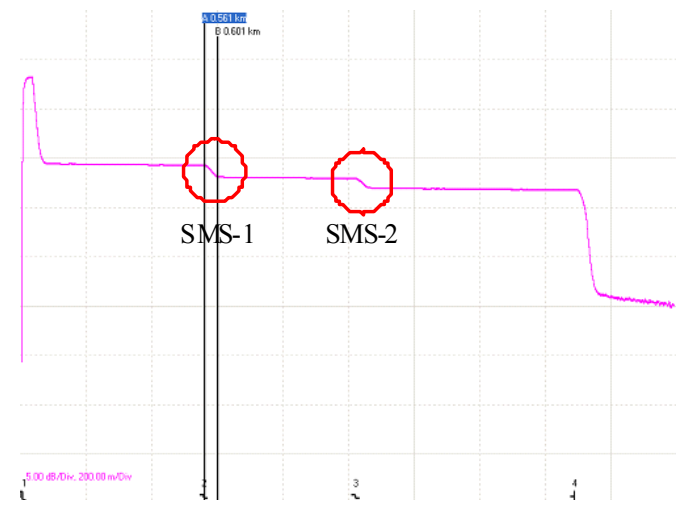

(a)

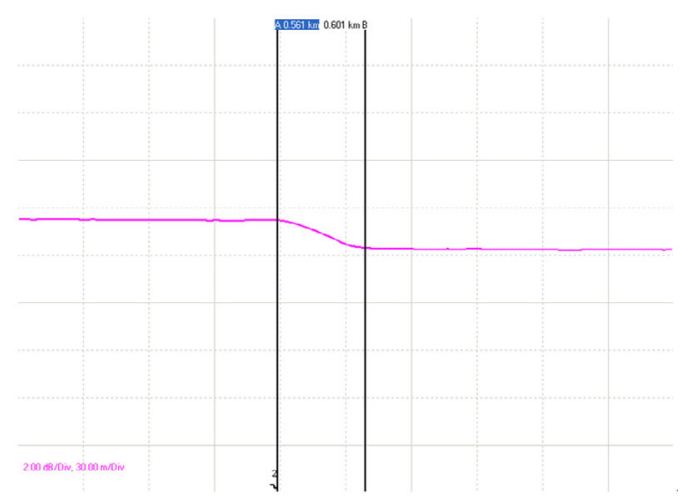

(b)

Fig. 2 A typical measurement result: (a) return loss response on the OTDR measurement where a non-reflective event appears due to the SMS fiber structure and the applied displacement and (b) zooming in the return loss for the non-reflective event.
In the SMS fiber structure with an MMF length of about $1 \mathrm{~m}$, there are two splicings of SMF to MMF and MMF to SMF, and it should appear as two non-reflective events in the OTDR trace. Meanwhile, the applied displacement in the MMF part causes the multimode interference variation [8], and in turn it also induces a non-reflective event. However, since a spatial resolution of the OTDR is larger than that in the MMF section, it appears as one event only. In this work, the OTDR was tuned at the pulse width of $300 \mathrm{~ns}$, which corresponds to the spatial resolution of $30 \mathrm{~m}$.

In this paper, the applied displacement is given in the MMF part of the SMS fiber structure as shown in Fig. 1(b), and it is assumed that there is no disturbance in other parts in the fiber network. However, if there is any disturbance such as a bending in the SMF part, the bending radius should be maintained and larger than $75 \mathrm{~mm}$ to avoid a readable return loss in the OTDR trace [13].

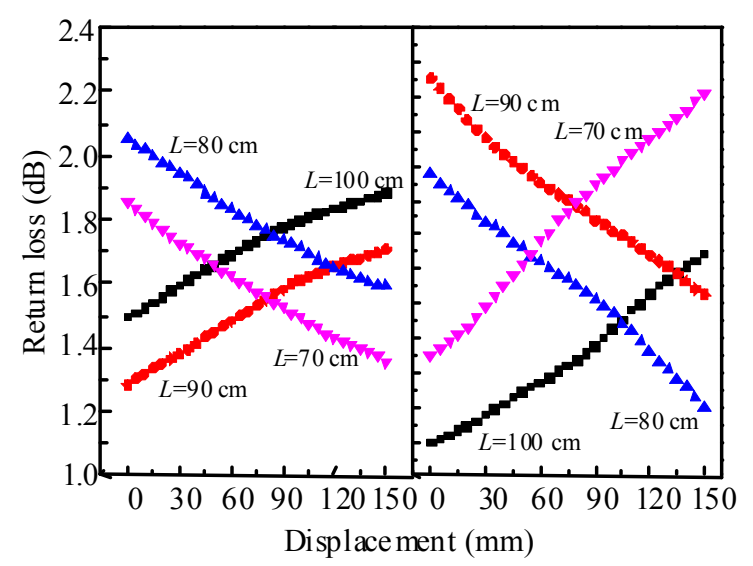

(a)

(b)

Fig. 3 Return loss due to the applied displacement of the (a) straight configuration and (b) sinusoidal configuration.

Figure 3(a) shows the return loss due to the applied displacement from $0 \mathrm{~mm}$ to $150 \mathrm{~mm}$ for the first arrangement of the straight SMS fiber structure configuration with the MMF length of $100 \mathrm{~cm}$, $90 \mathrm{~cm}, 80 \mathrm{~cm}$, and $70 \mathrm{~cm}$. It can be seen that the return loss depends on the MMF length of the SMS fiber structure. The displacement sensor characteristic can be specified by the parameters of 
sensitivity, linearity $\left(R^{2}\right)$ and resolution. Table 1 presents the displacement sensor's characteristic for various MMF lengths. The displacement sensors with the MMF length of $100 \mathrm{~cm}$ and $90 \mathrm{~cm}$ have a positive slope while those with the MMF length of $80 \mathrm{~cm}$ and $70 \mathrm{~cm}$ have a negative slope. It is found that the shortest MMF length of $70 \mathrm{~cm}$ has the highest sensitivity of $3.293 \mathrm{mdB} / \mathrm{mm}$, linearity of 0.994 , and a resolution of $0.304 \mathrm{~mm}$ assuming the OTDR can detect minimum value of $0.001 \mathrm{~dB}$.

Table 1 Displacement sensor characteristic for the straight arrangement.

\begin{tabular}{cccc}
\hline $\begin{array}{c}\text { MMF length } \\
(\mathrm{cm})\end{array}$ & $\begin{array}{c}\text { Sensitivity } \\
(\mathrm{mdB} / \mathrm{mm})\end{array}$ & $\begin{array}{c}\text { Resolution } \\
(\mathrm{mm})\end{array}$ & $\begin{array}{c}\text { Linearity } \\
\left(R^{2}\right)\end{array}$ \\
\hline 100 & 2.573 & 0.389 & 0.983 \\
90 & 2.787 & 0.359 & 0.989 \\
80 & 3.087 & 0.324 & 0.992 \\
70 & 3.293 & 0.304 & 0.994 \\
\hline
\end{tabular}

Figure 3(b) presents the return loss due to the applied displacement for the sinusoidal arrangement of the SMS fiber structure as specified in the previous section with the MMF length of $100 \mathrm{~cm}$, $90 \mathrm{~cm}, 80 \mathrm{~cm}$, and $70 \mathrm{~cm}$. One can see the return loss also depends on the MMF length of the sinusoidal arrangement. The displacement sensors with the MMF length of $100 \mathrm{~cm}$ and $70 \mathrm{~cm}$ have a positive slope while those with the MMF length of $90 \mathrm{~cm}$ and $80 \mathrm{~cm}$ have a negative slope. Table 2 presents the displacement sensor's characteristic with the sinusoidal configuration for various MMF lengths. It is shown that the shortest MMF length of $70 \mathrm{~cm}$ has the highest sensitivity of $5.073 \mathrm{mdB} / \mathrm{mm}$, a linearity of 0.995 , and a resolution of $0.197 \mathrm{~mm}$. From Tables 1 and 2, one can compare that the use of sinusoidal arrangement of the SMS fiber structure can increase the sensitivity of the displacement sensor.

Table 2 Displacement sensor characteristic for the sinusoidal arrangement.

\begin{tabular}{cccc}
\hline $\begin{array}{c}\text { MMF length } \\
(\mathrm{cm})\end{array}$ & $\begin{array}{c}\text { Sensitivity } \\
(\mathrm{mdB} / \mathrm{mm})\end{array}$ & $\begin{array}{c}\text { Resolution } \\
(\mathrm{mm})\end{array}$ & Linearity $\left(R^{2}\right)$ \\
\hline 100 & 3.667 & 0.273 & 0.989 \\
90 & 4.173 & 0.240 & 0.992 \\
80 & 4.560 & 0.219 & 0.994 \\
70 & 5.073 & 0.197 & 0.995 \\
\hline
\end{tabular}

The sensitivity of the displacement sensor can be varied by changing the distance between two permanent poles. The influence of the distance between two permanent poles on the return loss for the sinusoidal arrangement with the MMF length of $70 \mathrm{~cm}$ is shown in Fig. 4. It is depicted that the return loss due to the displacement for the distance between two permanent poles is $R=70 \mathrm{~cm}, 60 \mathrm{~cm}$, $50 \mathrm{~cm}$, and $40 \mathrm{~cm}$. The sensor's characteristic is presented in Table 3. It is found that the shortest distance between two permanent poles is $R=40 \mathrm{~cm}$, which has the highest sensitivity of $6.293 \mathrm{mdB} / \mathrm{mm}$ and the linearity of 0.998 .

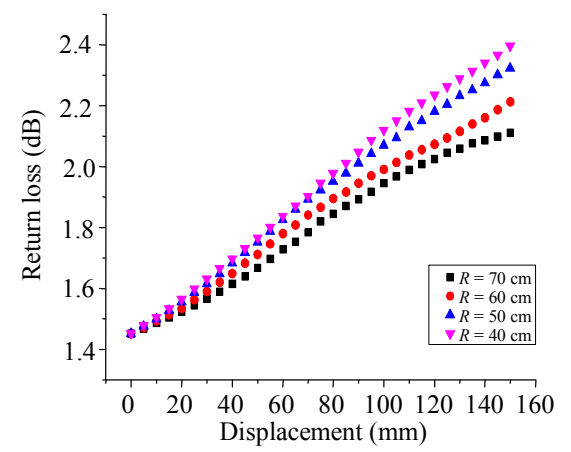

Fig. 4 Effect of the distance between two permanent poles on the return loss at a fixed MMF length of $70 \mathrm{~cm}$ with sinusoidal configuration.

Table 3 Displacement sensor characteristic for the sinusoidal arrangement with a fixed MMF length of $70 \mathrm{~cm}$ and distance variations of the two permanent poles.

\begin{tabular}{cccc}
\hline $\begin{array}{c}\text { Distance of two } \\
\text { permanent poles }(\mathrm{cm})\end{array}$ & $\begin{array}{c}\text { Sensitivity } \\
(\mathrm{mdB} / \mathrm{mm})\end{array}$ & $\begin{array}{c}\text { Resolution } \\
(\mathrm{mm})\end{array}$ & $\begin{array}{c}\text { Linearity } \\
\left(R^{2}\right)\end{array}$ \\
\hline 70 & 4.393 & 0.228 & 0.992 \\
60 & 5.073 & 0.197 & 0.995 \\
50 & 5.807 & 0.172 & 0.997 \\
40 & 6.293 & 0.159 & 0.998 \\
\hline
\end{tabular}

It is known that the SMS fiber structure is sensitive to the temperature and other parameters such as strain or displacement which can cause a cross-sensitivity problem. The cross-sensitivity of the SMS fiber structures was investigated previously $[8,14,15]$. It is found that for the strain or displacement measurement, the temperature dependence can induce the strain or displacement error $[8,14,15]$. However, the temperature-induced displacement measurement error can be minimized 
by selecting a proper material with a certain concentration of $\mathrm{GeO}_{2}$ and $\mathrm{P}_{2} \mathrm{O}_{5}$ in the core region of the MMF [14]. It can also be minimized by applying a self-temperature monitoring using a temperature sensor, and thus the temperature information is used to determine a displacement value based on a suitable calibration of displacement responses with temperature variations [15].

An advantage of utilizing the OTDR as an interrogator is a possibility to perform a simultaneous quasi-distributed displacement measurement [10]. Several displacement sensors can be located within the optical fiber network. A maximum possible number of displacement sensors depend on a dynamic measurement range of the OTDR and a discrimination range of the displacement sensor. For example, when a commercial OTDR has the dynamic range of $45 \mathrm{~dB}$ and the displacement sensor has the discrimination range of about $1 \mathrm{~dB}$, the system can provide the maximum simultaneous displacement measurement of about 45 sensors.

The proposed displacement measurement system provided a low cost and simple sensor with a long range displacement measurement capability. The use of the OTDR-based interrogator can offer the quasi-distributed measurement which is very useful to monitor the displacement in many applications such as for the civil structures monitoring.

\section{Conclusions}

The SMS fiber structure with straight and sinusoidal configurations for the long-range displacement sensor using the OTDR-based interrogator is proposed and investigated. The SMS fiber structure is installed on a flexible plate between two permanent poles. It is shown that the return loss due to the applied displacement depends on the MMF length of the SMS fiber structure. It is found that the shortest MMF length has the highest sensitivity of the displacement measurement, and the use of sinusoidal arrangement of the SMS fiber structure can increase the sensitivity. A shorter distance between two permanent poles can also provide a higher sensitivity. It is demonstrated that the SMS fiber structure with the sinusoidal configuration, the MMF length of $70 \mathrm{~cm}$, and the distance of two permanent poles of $40 \mathrm{~cm}$, can perform the displacement measurement with the range from $0 \mathrm{~mm}$ to $150 \mathrm{~mm}$, the sensitivity about $6.293 \mathrm{mdB} / \mathrm{mm}$, and the linearity of 0.998 . By using the OTDR-based interrogator, the quasi-distributed displacement measurement can be carried out for many applications such as the civil structures monitoring.

\section{Acknowledgement}

This research was supported by "Hibah Penelitian Unggulan ITS - 2012" Contract No. 0392.36/IT2.7/PM/2012.

Open Access This article is distributed under the terms of the Creative Commons Attribution License which permits any use, distribution, and reproduction in any medium, provided the original author(s) and source are credited.

\section{References}

[1] B. Lee, "Review of the present status of optical fiber sensors," Optical Fiber Technology, 2003, 9(2): $57-79$.

[2] M. Majumder, T. K. Gangopadhyay, A. K. Chakraborty, K. Dasgupta, and D. K. Bhattacharya, "Fibre Bragg gratings in structural health monitoring - present status and applications," Sensors and Actuators A: Physical, 2008, 147(1): 150-164.

[3] H. Gnewuch, E. Smeu, D. A. Jackson, and A. G. Podoleanu, "Long range extensometer for civil structure monitoring using fibre Bragg gratings," Measurement Science and Technology, 2005, 16(10): 2005-2010.

[4] K. O. Hill and G. Meltz, "Fiber Bragg grating technology fundamentals and overview," Journal of Lightwave Technology, 1997, 15(8): 1263-1276.

[5] Y. Zhao and Y. Liao, "Discrimination methods and demodulation techniques for fiber Bragg grating sensors," Optics Lasers in Engineering, 2004, 41(1): $1-18$.

[6] D. Đonlagić and M. Završnik, "Fiber-optic microbend 
sensor structure," Optics Letters, 1997, 22(11): 837-839.

[7] A. Kumar, R. K. Varshney, and R. Kumar, "SMS fiber optic microbend sensor structures: effect of the modal interference," Optics Communications, 2004, 232(1-6): 239-244.

[8] Q. Wu, A. M. Hatta, P. Wang, Y. Semenova, and G. Farrell, "Use of a bent single SMS fiber structure for simultaneous measurement of displacement and temperature sensing," IEEE Photonics Technology Letters, 2011, 23(2): 130-132.

[9] A. M. Hatta, Y. Semenova, G. Rajan, and G. Farrell, "A voltage sensor based on a singlemode-multimodesinglemode fiber structure," Microwave and Optical Technology Letters, 2010, 52(8): 1887-1890.

[10] Q. Wu, A. M. Hatta, Y. Semenova, and G. Farrell, "Use of a single-multiple-single-mode fiber filter for interrogating fiber Bragg grating strain sensors with dynamic temperature compensation," Appied Optics, 2009, 48(29): 5451-5458.

[11] A. M. Hatta, H. E. Permana, H. Setijono, A. Kusumawardhani, and Sekartedjo, "Strain measurement based on SMS fiber structure sensor and OTDR," Microwave and Optical Technology Letters, 2013, 55(11): 2576-2578.

[12]A. M. Hatta, K. Indriawati, T. Bestariyan, T. Humada, and Sekartedjo, "SMS fiber structure for temperature measurement using an OTDR," Photonics Sensors, 2013, 3(3): 262-266.

[13] N. M. P. Pinto, O. Frazao, J. M. Baptista, and J. L. Santos. "Quasi-distributed displacement sensor for structural monitoring using a commercial OTDR," Optics and Lasers in Engineering, 2006, 44(8): 771-778.

[14] S. M. Tripathi, A. Kumar, R. K. Varshney, Y. Kumar, E. Marin, and J. P. Meunier, "Strain and temperature sensing characteristics of single-mode-multimodesingle-mode structures," Journal of Lightwave Technology, 2009, 27(13): 2348-2356.

[15] A. M. Hatta, Y. Semenova, Q. Wu, and G. Farrell. "Strain sensor based on a pair of single-modemultimode-single-mode fiber structures in a ratiometric power measurement scheme," Applied Optics, 2010, 49(3): 536-541. 